\title{
Effects of extracellular environment on the osmotic signal transduction involved in activation of motility of carp spermatozoa
}

\author{
G. Perchec Poupard ${ }^{1 *}$, J. L. Gatti ${ }^{2}$, J. Cosson ${ }^{3}$, C. Jeulin ${ }^{4}$, F. Fierville ${ }^{1}$ \\ and R. Billard ${ }^{1}$

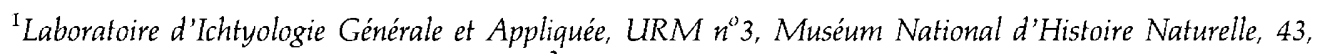 \\ rue Cuvier, 75231 Paris Cedex 05, France; Institut National de Recherche Agronomique-Centre National \\ de Recherche Scientifique, URA 1291, Laboratoire de Physiologie de la Reproduction, 37380 Monnaie, \\ France; ${ }^{3}$ Centre National de Recherche Scientifique, URA 671, Station marine, 06230 Villefranche/mer, \\ France; and ${ }^{4}$ Laboratoire de Biologie de la Reproduction et du Développement, Centre Hospitalier \\ Universitaire, 94275 Kremlin-Bicêtre Cedex, France
}

The mechanism by which a hypo-osmotic shock activates motility of carp spermatozoa was studied. The direct role of osmolality at the axoneme was investigated after demembranation of spermatozoa with Triton X-100 and reactivation in various ionic or anionic solutions containing Mg-ATP: demembranated spermatozoa remain motile in solutions of osmolality up to $550 \mathrm{mOsm} \mathrm{kg}^{-1}$ while non-demembranated spermatozoa are immotile when

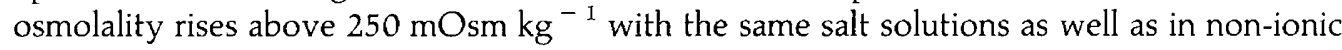
solutions. Suspension in hypo-osmotic saline solutions triggered the swelling of native carp spermatozoa. No motility or swelling occurred above $200-300 \mathrm{mOsm} \mathrm{kg}^{-1}$ and this osmolality is probably that of the cytosol. The swelling of carp spermatozoa is the result of an entrance of water but this was not affected by pCMBS, an inhibitor of the aquaporin CHIP28, or by various inhibitors of the co-transport of water with ions. Various pharmacological agents that affect the motility of different sperm species had no effect on carp sperm motility when used under similar conditions. However, prolonged exposure to a solution devoid of $\mathrm{K}^{+}$or $\mathrm{Cl}^{-}$affects the activation of motility in a reversible manner, suggesting that these ions have a role in the perception or transduction of the osmotic signal. Altering the concentration of intracellular second messengers such as $\mathrm{Ca}^{2+}$ and cAMP, and the $\mathrm{pH}$ did not affect the motility of carp spermatozoa. However, DMSO at $1-20 \%\left(400-3200 \mathrm{mOsm} \mathrm{kg}{ }^{-1}\right)$ affects the motility of carp spermatozoa 3-4 min after mixing. These results show that the activation signal of carp sperm motility differs from that known for spermatozoa of other species of fish such as trout. Our results indicate that the activation mechanism may involve a co-transport of ions or specific 'stretch-activated channels' that are sensitive to osmotic pressure.

\section{Introduction}

Fish spermatozoa remain quiescent in the genital tract and in the seminal plasma in most species that have external fertilization. They become transiently motile at spawning when released into the surrounding water. Most of the studies on the regulation of activation of motility were carried out on trout spermatozoa. These cells become motile as a result of changes in the properties of the plasma membrane potential and its ionic conductance (Cosson et al., 1989; Gatti et al., 1990; Boitano and Omoto, 1991, 1992; Tanimoto et al., 1994), due to a decrease in the concentration of extracellular $\mathrm{K}^{+}$(Morisawa et al., 1983a; Stoss, 1983; Tanimoto et al., 1994). These membrane modifications induce intracellular changes in the

*Correspondence.

Received 18 December 1996 cascade of second messengers such as cAMP, calcium, in $\mathrm{pH}$, or in protein phosphorylation (Morisawa and Ishida, 1987; Cosson et al., 1989; Boitano and Omoto, 1991, 1992) which then lead to activation of axonemal movement.

Ionic effects at the plasma membrane are not the universal triggering agent of fish sperm motility. An alternative regulation mechanism involves osmotic variation in the environment. Spermatozoa of the marine puffer fish are quiescent in their seminal plasma (around $300 \mathrm{mOsm} \mathrm{kg}{ }^{-1}$ ) and become motile when there is an increase in the osmolality of the surrounding medium (1200 mOsm kg ${ }^{-1}$ ) (Oda and Morisawa, 1993). This hyperosmotic shock could induce an increase in the intracellular $\mathrm{K}^{+}$(Takai and Morisawa, 1995) and in the $\mathrm{Ca}^{2+}$ concentration, and an internal acidification (Oda and Morisawa, 1993). It has been proposed that these series of variations are the trigger for the activation of motility. Conversely, the motility of carp 
spermatozoa is inhibited by the high osmolality present in the seminal plasma $\left(300 \mathrm{mOsm} \mathrm{kg}^{-1}\right.$ : Morisawa et al., 1983b; Redondo-Müller et al., 1991; Perchec et al., 1995); exposure to hypo-osmotic media with osmolality $<200 \mathrm{mOsm} \mathrm{kg}^{-1}$, irrespective of the ionic composition, triggers sperm motility. This low osmolality also induces swelling in the sperm cells, leading to disruption of the plasma membrane in freshwater because the osmotic shock is too great (Billard, 1978; Morisawa et al., 1983b; Perchec et al., 1996). It was suggested that the osmotic shock modifies membrane permeability and organization of the lipid bilayer (Marian et al., 1993). Other results suggest that an efflux of $\mathrm{K}^{+}$ions through $\mathrm{K}^{+}$channels is involved in the activation (Krasznai et al., 1995) and the decrease in the intracellular $\mathrm{K}^{+}$concentration may trigger the activation of spermatozoa of freshwater zebrafish (Takai and Morisawa, 1995).

Taken together, these observations indicate that the mechanism for activating carp spermatozoa is still poorly understood compared with the ionic mechanism described for trout spermatozoa. More information about the osmotic response is available on cellular types like erythrocytes (Lauf, 1982; Dickman and Goldstein, 1990), plant cells, bacteria (Csonka, 1989) and yeast (Hosono, 1992; Berner and Gervais, 1994). In response to hypo-osmotic stress, these cells swell as a result of the influx of water into the cytoplasm which is then followed, in contrast to sperm cells, by a biochemical readjustment that restores the initial cell volume by changing the concentration of intracellular electrolytes (such as $\mathrm{K}^{+}, \mathrm{Na}^{+}, \mathrm{Ca}^{2+}, \mathrm{Cl}^{-}$) or of nonelectrolyte (like amino acid, glycerol, sorbitol, inositol) solute concentration.

In the present study, the effect of osmotic shock on the initiation of motility of carp spermatozoa was tested directly at the axoneme using demembranated-reactivated sperm cells. The relationship between the changes in sperm volume and the activation of motility was also studied. In addition, the role of water and ions in the activation process and the intervention of an intracellular second messenger were investigated using some pharmacological agents.

\section{Materials and Methods}

\section{Collection of spermatozoa}

Male carp (Cyprinus carpio) weighing between 0.9 and $1.5 \mathrm{~kg}$ were obtained from INRA (Jouy en Josas), and from a private fish farm (M. de Courson, Champagne Ardennes). Fish were kept in $2 \mathrm{~m}^{3}$ tanks under natural photoperiod and temperature. Water was renewed twice a day (flow rate of $31 \mathrm{~min}^{-1}$ ) and the fish were fed with carp pellet food every other day.

Spermiation started 12-24 h after injecting $0.2 \mathrm{ml}$ Ovaprim (Syndell Laboratories Ltd) $\mathrm{kg}^{-1}$ body weight i.p. (4 $\mu \mathrm{g} \mathrm{Arg}^{6}$ Pro ${ }^{9}$ NEt GnRH). Semen was collected daily for the next 3 or 4 days by applying abdominal pressure to males anaesthetized with $0.5 \mathrm{ml}$ 2-phenoxyethanol $\mathrm{l}^{-1}$. Milt contamination by water, urine or faeces was carefully avoided. Semen was collected into individual $5 \mathrm{ml}$ tubes and kept on ice.

\section{Analysis of motility}

The movements of carp spermatozoa were recorded at 50 frames per second using a camcorder (canovision EX $1 \mathrm{Hi}$,
Canon) and a dark-field microscope (Olympus BH-L objective $\times 20$ ) illuminated by a stroboscope light source (Chadwick Helmut Strobex). The focal plane was always positioned near the surface of the glass slide. Spermatozoa were visualized on a video monitor (Panasonic BT-M1420PY) at a final magnification of $\times 750$ on the screen. Video records were analysed frame by frame. The slide (without coverslip) was coated with $1 \%$ poly-vinyl alcohol to prevent spermatozoa from sticking. Observations were made at room temperature.

The percentage of motile spermatozoa (with progressive forward motility) was calculated $30 \mathrm{~s}$ after activation by measurements on successive video frames.

The curvilinear velocity of spermatozoa was determined $30 \mathrm{~s}$ after activation in a medium that allowed sperm motility. After $30 \mathrm{~s}$ of motility, carp spermatozoa still have a high velocity in saline solution (Perchec et al., 1995). The delay of $30 \mathrm{~s}$ was essential to ensure that at the time of the recording the focus was adjusted and that a large number of spermatozoa was in the field. For $1 \mathrm{~s}$, the successive positions of the sperm heads of ten different spermatozoa were drawn on transparent paper placed on the video screen so that the tracking analysis of head trajectories could be analysed. Spermatozoa were randomly chosen from a homogeneous population.

\section{Demembranation and reactivation of spermatozoa}

The reactivated spermatozoa were prepared after a two-step dilution procedure adapted from Cosson and Gagnon (1988). The plasma membrane was first removed by adding $10 \mu \mathrm{l}$ of intact spermatozoa to $990 \mu \mathrm{l}$ of a Triton demembranating solution. After $30 \mathrm{~s}, 1 \mu \mathrm{l}$ of the permeabilized spermatozoa was placed directly under the stage of the microscope in $20 \mu \mathrm{l}$ of the reactivating solution.

Four different demembranating and reactivating solutions were prepared, the major compounds of which were either ionic $(\mathrm{KCl}, \mathrm{NaCl}$ or choline chloride) or non-ionic (glucose). The potassium demembranating solution comprised: $0.05-0.45 \mathrm{~mol} \mathrm{KCl} \mathrm{l}^{-1}, 20 \mathrm{mmol}$ Tris- $\mathrm{HCl} \mathrm{l}{ }^{-1}, 0.5 \mathrm{mmol}$ EDTA $\mathrm{l}^{-1}, 0.1 \mathrm{mmol}$ EGTA $\mathrm{l}^{-1}, 1 \mathrm{mmol}$ dithiothreitol $\mathrm{l}^{-1}$ and $0.04 \%(\mathrm{w} / \mathrm{v})$ Triton $\mathrm{X}-100, \mathrm{pH} 8.2$. For the other media, potassium was omitted and substituted with $\mathrm{NaCl}$, choline chloride or glucose. The reactivation solution comprised $20 \mathrm{mmol}^{\text {Tris- }} \mathrm{HCl} \mathrm{l}^{-1}, 0.5 \mathrm{mmol}$ EGTA $\mathrm{l}^{-1}, 1 \mathrm{mmol}$ dithio-

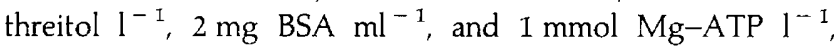
$\mathrm{pH} 8.2$, as well as 0.05 to $0.45 \mathrm{~mol} \mathrm{l}^{-1} \mathrm{KCl}, \mathrm{NaCl}$, choline chloride or glucose. The osmolality of these media ranged from 100 to $880 \mathrm{mOsm} \mathrm{kg}^{-1}$ according to the concentration of the major compound. In addition, a demembranating and a reactivating solution with osmolalities of $60 \mathrm{mOsm} \mathrm{kg} \mathrm{kg}^{-1}$ were prepared as described above but omitting glucose or the major salt $(\mathrm{NaCl}, \mathrm{KCl}$ or choline chloride).

The influence of osmolality on intact spermatozoa was studied after the same two-step dilution procedure using the following media. The first solution had a high osmolality (300 mOsm kg ${ }^{-1}$ ), to maintain the sperm quiescence. The ionic solution comprised $0.15 \mathrm{~mol} \mathrm{l}^{-1} \mathrm{KCl}, \mathrm{NaCl}$ or choline chloride, $20 \mathrm{mmol}^{\text {Tris- }} \mathrm{HCl} \mathrm{l}^{-1}, 0.5 \mathrm{mmol}^{-1}$ EDTA $^{-1}, 0.1 \mathrm{mmol}$ EGTA $\mathrm{l}^{-1}$ and 1 mmol dithiothreitol $\mathrm{l}^{-1}, \mathrm{pH}$ 8.2. In media containing glucose, salts were omitted and substituted by $0.25 \mathrm{~mol}$ 
glucose $1^{-1}$. After $30 \mathrm{~s}$, the second dilution was performed in the media described for demembranated spermatozoa.

\section{Measurement of cell swelling}

The change in the volume of carp spermatozoa in relation to the osmotic gradient was performed by a spermatocrit method. Semen from two or three males were pooled to increase the volume of the semen samples and was then centrifuged for $15 \mathrm{~min}$ at $600 \mathrm{~g}$ to reduce the seminal plasma volume by half. The concentrated semen was then diluted $1 / 10$ in various saline $(\mathrm{KCl}, \mathrm{NaCl}$ or choline chloride) or glucose solutions in which the concentration ranged from 0 to $0.45 \mathrm{~mol} \mathrm{l}^{-1}$ (buffered with $30 \mathrm{mmol}$ Tris- $\mathrm{HCl} 1^{-1}, \mathrm{pH} 8.0$, osmolality from 40 to $800 \mathrm{mOsm} \mathrm{kg}^{-1}$ ).

Spermatozoa were also diluted in a DMSO solution containing: $0-20 \%(\mathrm{v} / \mathrm{v})$ dimethylsulfoxide (DMSO), $50 \mathrm{mmol}$ $\mathrm{KCl}{ }^{-1}, 30 \mathrm{mmol}$ Tris- $\mathrm{HCl} \mathrm{l}^{-1}$, and glucose to adjust the osmolality to between 400 and $3400 \mathrm{mOsm} \mathrm{kg}^{-1}$.

The diluted semen was introduced into an haematocrit tube (diameter 1.1-1.2 mm, length $75 \mathrm{~mm}$ ) and then centrifuged for $10 \mathrm{~min}$ at $1500 \mathrm{~g}$. The percentage volume occupied by spermatozoa in each medium was calculated based on the volume of $10^{10}$ spermatozoa in a solution of $0.2 \mathrm{~mol} \mathrm{KCl}^{-1}$ which has routinely been used to maintain the quiescence of carp spermatozoa (Redondo-Müller et al., 1991; Perchec et al., 1993, 1995).

During centrifugation with the glucose solution, the plasma membrane of the spermatozoa was disrupted and so no values could be obtained.

\section{Kinetics of head swelling in distilled water}

For measuring the kinetics of head swelling, a zoom lens was fixed to the camera, allowing a final magnification of $\times 2100$ on the video monitor screen. Semen was first diluted $(1 / 100)$ in a potassium saline solution $\left(200 \mathrm{mmol} \mathrm{KCl} \mathrm{l^{-1 }}, 30 \mathrm{mmol}\right.$ Tris- $\mathrm{HCl} \mathrm{l}^{-1}, \mathrm{pH} 8.0$; osmolality $390 \mathrm{mOsm} \mathrm{kg}^{-1}$ ) in which they remain quiescent. Spermatozoa were activated directly under the microscope stage, and $1 \mu \mathrm{l}$ of the above sperm suspension was diluted with $19 \mu \mathrm{l}$ of cold distilled water (final osmolality $20 \mathrm{mOsm} \mathrm{kg}^{-1}$ ) to delay the activation. The diameters of the heads of ten spermatozoa were measured using a calliper square, and averaged at different times after activation. Measurements were made every $3-5 \mathrm{~s}$ during the first $20 \mathrm{~s}$ of activation and then every $15 \mathrm{~s}$ for $2 \mathrm{~min}$. After activation for $1 \mathrm{~min}, 5 \mu \mathrm{KCl}\left(1 \mathrm{~mol} \mathrm{l}^{-1}\right)$ was added, increasing the osmolality to $370 \mathrm{mOsm} \mathrm{kg}{ }^{-1}$. The head diameter was measured every $2 \mathrm{~s}$ for $10 \mathrm{~s}$ and then after $10 \mathrm{~s}$.

\section{Modification of the transmembrane ionic exchange}

Carp spermatozoa were first diluted 1/100 in medium 1 that comprised $50 \mathrm{mmol} \mathrm{l}^{-1} \mathrm{KCl}$ or $\mathrm{NaCl}, 30 \mathrm{mmol}$ Tris- $\mathrm{HCl} \mathrm{l}^{-1}$, $\mathrm{pH} \mathrm{8.0,} \mathrm{and} \mathrm{glucose} \mathrm{to} \mathrm{adjust} \mathrm{the} \mathrm{osmolality} \mathrm{to} 390 \mathrm{mOsm}$ $\mathrm{kg}^{-1}$, so that the cells were immotile. Pharmacological agents were present in this medium at the concentrations given in Tables 1-4 (see below). In case the motility was not triggered in these media, the capacity for motility was tested at various times after mixing, in medium 2 (dilution rate $1 / 20$ ) containing the same concentration of pharmacological agents in a solution composed of $50 \mathrm{mmol} \mathrm{l^{-1 }} \mathrm{KCl}$ or $\mathrm{NaCl}, 30 \mathrm{mmol}$ Tris- $\mathrm{HCl} 1^{-1}, \mathrm{pH} 8.0$, and glucose to adjust the osmolality to $170 \mathrm{mOsm} \mathrm{kg}^{-1}$.

Different categories of pharmacological agents were used to target the transport of water across the plasma membrane alone or coupled with ions (Table 1), the transmembrane transport of ions (Table 2), and the role of major ions (Table 3) and of intracellular second messengers in the activation of motility (Table 4). These pharmacological agents were administered at concentrations used in previous studies.

The role of the major ions $\mathrm{Na}^{+}, \mathrm{K}^{+}$and $\mathrm{Cl}^{-}$was investigated (Table 3) after a two-step dilution procedure. Carp spermatozoa were first diluted (1/100) in solutions of high osmolality $\left(390 \mathrm{mOsm} \mathrm{kg}^{-1}\right)$ containing glucose $(350 \mathrm{mmol}$ glucose $\mathrm{l}^{-1}, 30 \mathrm{mmol}$ Tris- $\mathrm{HCl} \mathrm{l}^{-1}, \mathrm{pH} 8.0$ ), choline chloride (200 mmol choline chloride $\mathrm{1}^{-1}, 30 \mathrm{mmol}$ Tris- $\mathrm{HCl} \mathrm{l}^{-1}$, $\mathrm{pH} 8.0)$ or sodium isethionate $(200 \mathrm{mmol}$ sodium isethionate $\mathrm{I}^{-1}, 30 \mathrm{mmol}$ Hepes $\left.\mathrm{I}^{-1}, \mathrm{pH} 8.0\right)$. Motility was tested after a second dilution step $(1 / 20)$ in a buffered solution of low osmolality ( $170 \mathrm{mOsm} \mathrm{kg}^{-1}$ ) containing the homologous compound: glucose (140 mmol glucose $1^{-1}, 30 \mathrm{mmol}$ Tris- $\mathrm{HCl}$ $\left.1^{-1}, \mathrm{pH} 8.0\right)$, choline chloride $\left(50 \mathrm{mmol}\right.$ choline chloride $\mathrm{l}^{-1}$, $30 \mathrm{mmol}$ Tris- $\mathrm{HCl} \mathrm{^{-1 }}, \mathrm{pH} 8.0$ ) or sodium isethionate $\left(50 \mathrm{mmol}\right.$ sodium isethionate $\mathrm{l}^{-1}, 30 \mathrm{mmol}$ Hepes $\mathrm{l}^{-1}$, $\mathrm{pH}$ 8.0).

The role of $\mathrm{NaCl}$ and $\mathrm{KCl}$ in the activation mechanism was investigated using a different protocol. After incubation for $10 \mathrm{~min}$ in the presence of glucose or choline chloride media with high osmolality ( $\left.390 \mathrm{mOsm} \mathrm{kg}{ }^{-1}\right), \mathrm{NaCl}$ or $\mathrm{KCl}$ (stock solution was $2 \mathrm{~mol}^{-1}$ ) was added separately up to a concentration of $100 \mathrm{mmol} \mathrm{l}^{-1}$. The incubation was then prolonged for $10 \mathrm{~min}$ and motility was checked by a $1 / 20$ dilution in a medium of low osmolality containing: $50 \mathrm{mmol}$ $\mathrm{KCl} 1^{-1}, 30 \mathrm{mmol}$ Tris- $\mathrm{HCl} 1^{-1}, \mathrm{pH} \mathrm{8.0,}$ osmolality $<170 \mathrm{mOsm} \mathrm{kg}{ }^{-1}$, or in distilled water.

\section{Pharmacological agents}

The pharmacological agents were purchased from Sigma (Saint Quentin Fallavier) except for tetraphenylphosphonium (TPP, Merck, Nogent sur Marne) and were either diluted in DMSO:ethanol (I:I) or in distilled water. In these experiments, the control diluant which contained $0.25 \%(\mathrm{v} / \mathrm{v})$ DMSO had no influence on motility.

\section{Statistical analysis}

Data are presented as means \pm SEM and were treated by an analysis of variance (ANOVA) with a significance level of $5 \%$ confidence.

\section{Results}

\section{Effect of osmolality on intact or demembranated spermatozoa}

Intact spermatozoa. Carp spermatozoa were fully motile $(95 \%)$ immediately after dilution in media with an osmolality 
(a)

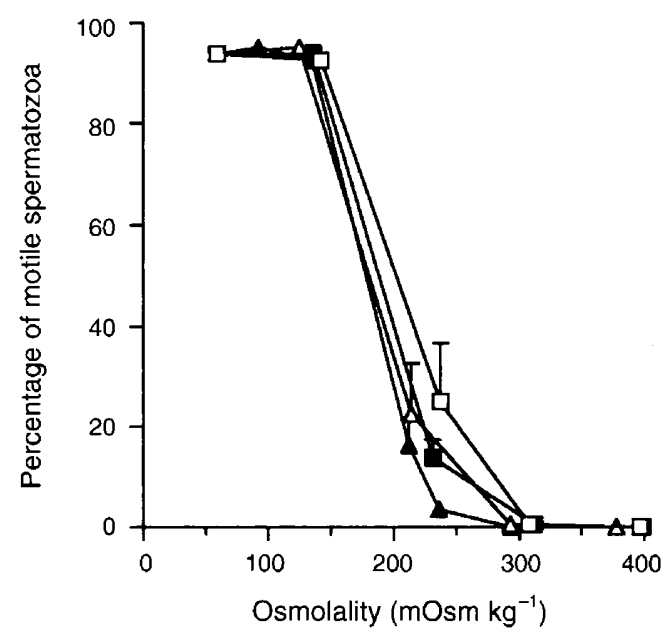

(b)

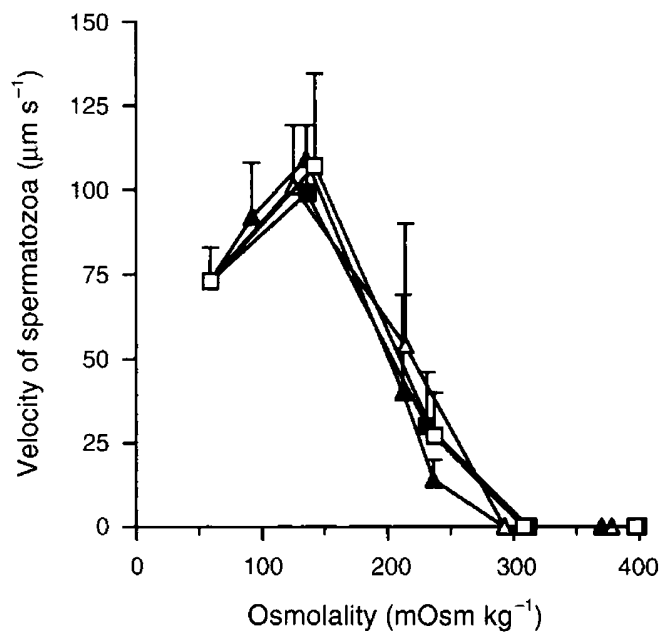

Fig. 1. (a) The percentage of motile carp spermatozoa and (b) their velocity as a function of osmolality and composition of the activating solution. Measurements were made $30 \mathrm{~s}$ after mixing with the activating solution containing $\mathrm{KCl}(\square), \mathrm{NaCl}(\boldsymbol{\square})$, choline chloride $(\Delta)$ or glucose $(\boldsymbol{\Delta})$. Each datum point represents the average of spermatozoa from three different males and ten spermatozoa per sample were observed (mean \pm SEM).

between 60 and $140 \mathrm{mOsm} \mathrm{kg}^{-1}$ (Fig. Ia) which corresponds to concentrations of $0-0.05 \mathrm{~mol} \mathrm{l}^{-1}$ of $\mathrm{NaCl}, \mathrm{KCl}$, choline chloride or $0-0.1 \mathrm{~mol} \mathrm{l}^{-1}$ of glucose-buffered solutions. Increasing the osmolality above $150 \mathrm{mOsm} \mathrm{kg}^{-1}$ strongly decreased the percentage of motile spermatozoa and only a few were activated at $200-230 \mathrm{mOsm} \mathrm{kg}{ }^{-1}$, irrespective of the composition of the solutions (ions or glucose). When the osmolality reached $300 \mathrm{mOsm} \mathrm{kg}{ }^{-1}$ (in solutions containing $0.15 \mathrm{~mol} \mathrm{salt} 1^{-1}$ or $0.25 \mathrm{~mol}$ glucose $1^{-1}$ ), all of the spermatozoa were immotile, but could be reversibly activated by decreasing the osmolality.

Spermatozoa displayed a forward motility up to $30 \mathrm{~s}$ after activation in all the ionic or non-ionic media tested with osmolalities between 60 and $140 \mathrm{mOsm} \mathrm{kg}^{-1}$ (Fig. 1b). Their velocity significantly increased $(P<0.05)$ from $73 \pm 10 \mu \mathrm{m} \mathrm{s}^{-1}$ to $105 \pm 19 \mu \mathrm{m} \mathrm{s}^{-1}$ and was quite similar in all the media. The velocity progressively decreased in parallel with sperm movement when osmolality was increased to $300 \mathrm{mOsm} \mathrm{kg}{ }^{-1}$.

Demembranated spermatozoa. When permeabilized spermatozoa were transferred into a reactivating medium of low ionic concentration $\left(0-0.05 \mathrm{~mol} \mathrm{l}^{-1}\right)$ with an osmolality between 60 and $140 \mathrm{mOsm} \mathrm{kg} \mathrm{kg}^{-1}$, or into a medium of low glucose concentration (Fig. 2a), the nucleus burst, while the axonemes apparently remained intact. In media devoid of $\mathrm{Na}^{+}$and $\mathrm{K}^{+}$ or containing only glucose, axonemal motility could be triggered only after addition of at least $25 \mathrm{mmol} \mathrm{l}^{-1} \mathrm{KCl}$ or $\mathrm{NaCl}$ (giving an osmolality of about $100 \mathrm{mOsm} \mathrm{kg}^{-1}$ ). This result shows that a low concentration of ions is not deleterious to the axonemal machinery as it remains functional even at low osmolality.

In the presence of $\mathrm{KCl}, \mathrm{NaCl}$ or choline chloride in the reactivating medium, $95 \%$ of demembranated spermatozoa were motile in media with an osmolality between 140 and

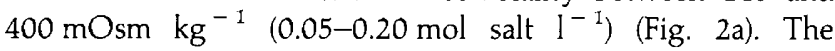
percentage of reactivated spermatozoa progressively decreases as the osmolality increases, and at $600-650 \mathrm{mOsm} \mathrm{kg} \mathrm{kg}^{-1}$
(0.30-0.35 mol salt $\left.1^{-1}\right)$, no axonemal movement was observed $30 \mathrm{~s}$ after dilution. At an osmolality of $480-$ $550 \mathrm{mOsm} \mathrm{kg}^{-1}\left(0.25-0.30 \mathrm{~mol} \mathrm{salt}^{-1}\right), 80-90 \%$ of spermatozoa were poorly motile $5 \mathrm{~s}$ after dilution; movement decreased rapidly and all were immotile $45-60 \mathrm{~s}$ later.

The velocity of spermatozoa measured $30 \mathrm{~s}$ after dilution in the saline reactivating media increased progressively in media of $60 \mathrm{mOsm} \mathrm{kg}{ }^{-1}$ up to a peak in media at $225 \mathrm{mOsm} \mathrm{kg} \mathrm{kg}^{-1}$ (0.1 mol salt $\mathrm{I}^{-1}$ ) (Fig. 2b). The maximum velocity depended on the ionic composition of the reactivating medium; velocity in media containing $\mathrm{KCl}\left(154 \pm 20 \mu \mathrm{m} \mathrm{s}^{-1}\right)$ or $\mathrm{NaCl}$ $\left(135 \pm 33 \mu \mathrm{m} \mathrm{s}^{-1}\right)$ was significantly higher $(P<0.05)$ than in choline chloride $\left(93 \pm 12 \mu \mathrm{m} \mathrm{s}^{-1}\right)$. At higher osmolalities $\left(600-650 \mathrm{mOsm} \mathrm{kg}^{-1}\right)$, the velocity decreases until complete immotility occurs.

\section{Measurement of volume change of intact spermatozoa}

Osmolality and swelling of spermatozoa. The volume of intact spermatozoa evaluated by a spermatocrit method $15 \mathrm{~min}$ after mixing with the different saline solutions decreased as the osmolality of the medium was increased, irrespective of the saline composition (Fig. 3). When spermatozoa are immotile, their volume remains identical to that of spermatozoa in the control buffered solution $\left(200 \mathrm{mmol} \mathrm{KCl}{ }^{-1}\right)$. The volume of motile spermatozoa decreased with the extracellular osmolality. The volume of spermatozoa in a Tris- $\mathrm{HCl}$ solution at $45 \mathrm{mOsm} \mathrm{kg}{ }^{-1}$ showed a 3.5 -fold increase without bursting. The threshold between activation and inhibition of motility (200-300 mOsm $\mathrm{kg}^{-1}$ ) corresponded approximately to the transition between swelling and not swelling.

Kinetics of sperm head swelling. Spermatozoa were kept immotile in a buffered solution of $200 \mathrm{mmol} \mathrm{KCl} \mathrm{l}^{-1}$ and the head diameter was measured on the video screen. When motility was triggered with distilled water (final osmolality 
(a)

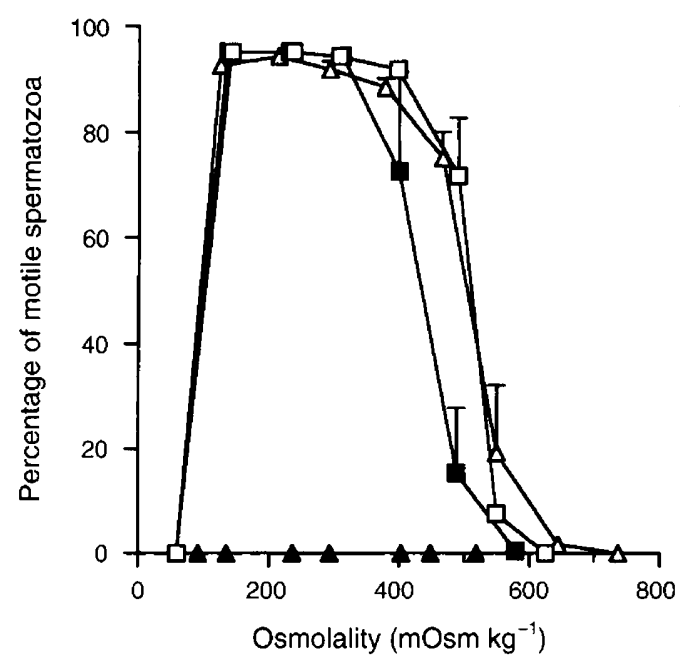

(b)

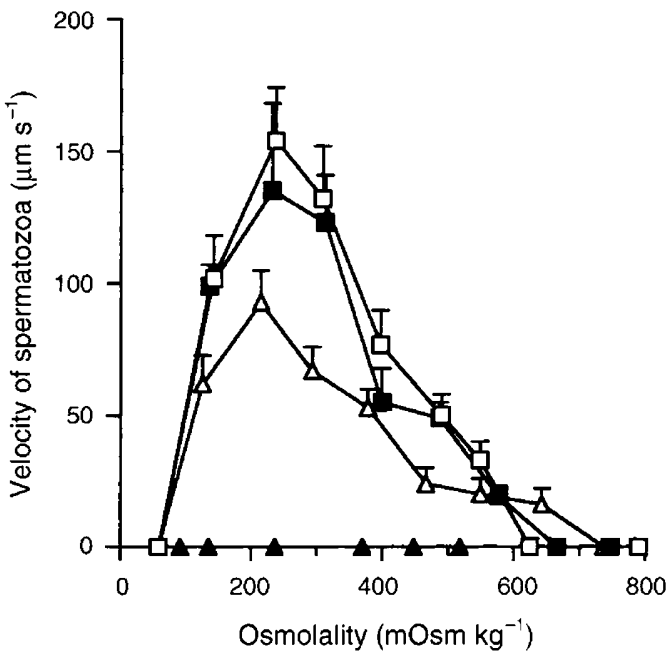

Fig. 2. Variation in (a) the percentage of motile carp demembranated spermatozoa and (b) their velocity as a function of osmolality and composition of the reactivating solution. Measurements were made $30 \mathrm{~s}$ after dilution in media containing $\mathrm{KCl}(\square), \mathrm{NaCl}(\boldsymbol{\square})$, choline chloride $(\triangle)$ or glucose $(\boldsymbol{\Delta})$. Values are means \pm SEM for three experiments performed and ten demembranated spermatozoa per sample were observed.

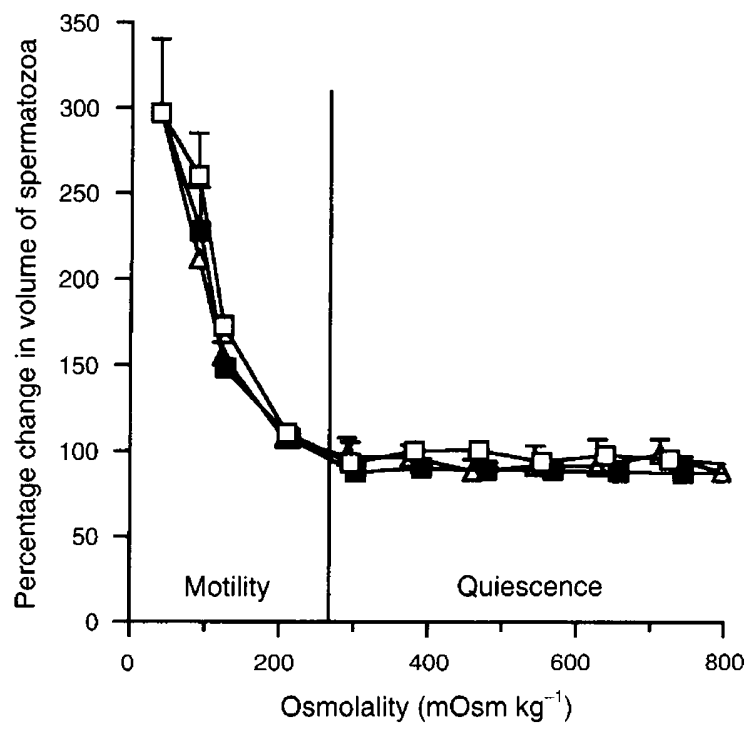

Fig. 3. Percentage change in volume of carp spermatozoa performed by a spermatocrit method. Spermatozoa were suspended in media of different osmolalities containing $\mathrm{KCl}(\square), \mathrm{NaCl}(\boldsymbol{\square})$ or choline chloride $(\triangle)$. The straight line represents the barrier between activation of motility or quiescence. Each datum point represent the average of two samples, each of which was obtained by pooling two different milt. At least two measurements were made per sample. Values are means \pm SD.

$20 \mathrm{mOsm} \mathrm{kg}^{-1}$ ), the head progressively increased in diameter during $60 \mathrm{~s}$ and then reached a plateau (Fig. 4). Increasing the osmolality of the medium, by adding $\mathrm{KCl}$ to a final osmolality of $370 \mathrm{mOsm} \mathrm{kg}{ }^{-1}$ stopped all sperm movement and triggered a shrinking of the sperm head, which recovered its initial volume within the next 3-4 s. This change can be reversed and motility of carp spermatozoa can be re-induced by decreasing the osmolality of the medium.

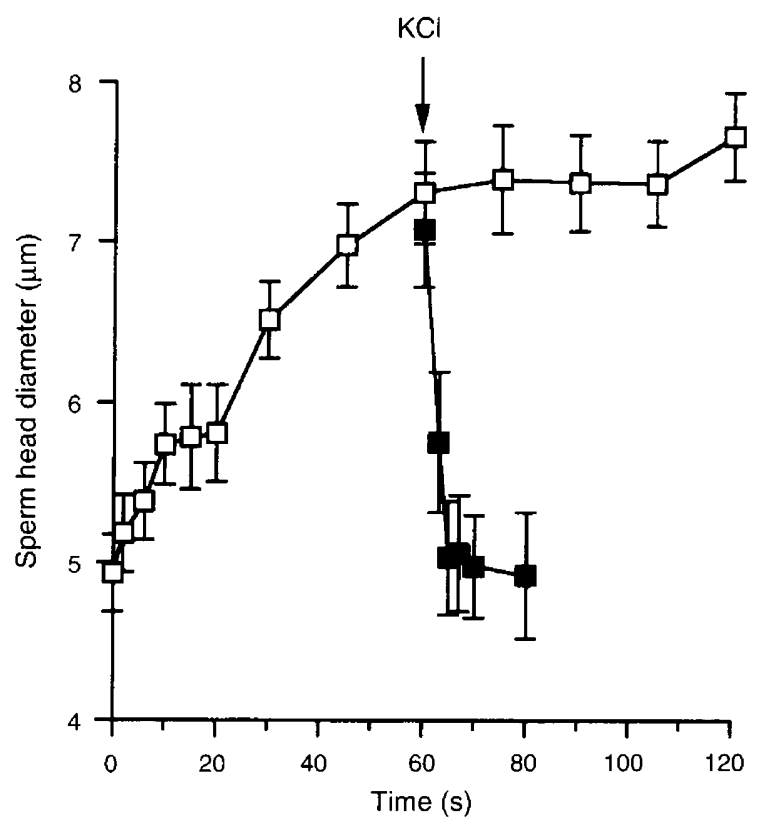

Fig. 4. The diameters of the heads of carp spermatozoa as a function of time after activation with cold distilled water ( $\square$ ). After $60 \mathrm{~s}$, motility was stopped by adding $5 \mu \mathrm{KCl}\left(\mathrm{I} \mathrm{mol} \mathrm{l}^{-1}\right)$ which increased the osmolality to $370 \mathrm{mOsm} \mathrm{kg}^{-1}$, and the shrinking of the head was measured ( $\boldsymbol{\square})$. Each datum point corresponds to the mean of measurements taken from spermatozoa of three different males, and an average of ten spermatozoa per sample was measured. Values are means \pm SEM.

\section{Transmembrane exchanges occurring at the activation step}

The transmembrane ionic or osmotic equilibrium that maintains the immotility of carp spermatozoa was manipulated to analyse the effect on sperm motility in media with high osmolality ( $>300 \mathrm{mOsm} \mathrm{kg}^{-1}$; medium 1) or low osmolality solution ( $<170 \mathrm{mOsm} \mathrm{kg}^{-1}$; medium 2). 
We first investigated the implication of water transport alone or water co-transported with ions or glucose across the plasma membrane in the activation process (Table 1). A specific inhibitor of the water channel CHIP28 $(28 \mathrm{kDa}$ channelforming integral protein), para-chloromercuribenzene sulfonate (pCMBS), which has been tested on the bovine red blood cell (Lahajnar et al., 1995), neither activates carp spermatozoa in a medium of high osmolality nor interferes with the subsequent activation in a medium of low osmolality. The use of the mammalian antidiuretic hormone arginine vasopressin (AVP), which increases water permeability in the renal collecting duct (Nielsen ef al., 1993), does not trigger the motility of carp spermatozoa incubated in a solution of $390 \mathrm{mOsm} \mathrm{kg}^{-1}$; nevertheless these spermatozoa can be further activated in a medium of $170 \mathrm{mOsm} \mathrm{kg}^{-1}$. The pharmacological agents bumetanide and furosemide that inhibit the co-transport of water and $\mathrm{KCl}$ across the epithelium (for review see Zeuthen and Stein, 1994) had no effect on carp spermatozoa either in a high or in a low osmolality medium. The inhibitors of anion-water co-transport, 4-4'-diisothiocyanato-stilbene-2,2'disulfonic acid (DIDS), which was tested in human erythrocytes (Blank et al., 1994) and 4-acetamido-4-isothiocyano-stilbene-22'-disulfonic acid (SITS) in human neutrophils (Korchak et al., 1980) have no effect on carp sperm activation.

For investigating the possible role of the glucose transporter (GLUT) as a water channel, which has been demonstrated in Xenopus oocytes and in mammalian spermatozoa (Fischbarg et al., 1990; Curry et al., 1995), cytochalasin B and phloretin were used: they have no effect on carp spermatozoa in conditions of high and low osmolality.

The effect of modifying the ionic transmembrane equilibrium on motility of carp spermatozoa are shown (Table 2). The various ionophores that were used are known to increase selectively the permeability to $\mathrm{K}^{+}$(valinomycin) or to catalyse the $\mathrm{Ca}^{2+}-\mathrm{H}^{+}$(A23187) and the $\mathrm{Na}^{+}-\mathrm{H}^{+}$exchange (monensin). These compounds did not stimulate the activation of carp spermatozoa under conditions of high osmolality or inhibit the activation in medium 2 . Reagents that affect $\mathrm{K}^{+}$ transport through channels, such as 4-aminopyridine, glybenclamide (Han et al., 1993) and $\mathrm{MgCl}_{2}$ (Lauf et al., 1992) did not interfere with the motility of spermatozoa in medium $I$ and subsequent activation in medium 2 . However, after incubation for $30 \mathrm{~min}$ in medium 1 with 4-aminopyridine, the period of motility in medium 2 containing the drug strongly decreased to less than $30 \mathrm{~s}$ compared with $10 \mathrm{~min}$ in the control. Ouabain, an inhibitor of the $\mathrm{Na} / \mathrm{K}-\mathrm{ATP}$ ase pump, did not interfere with motility. Two extracellular calcium chelators EGTA and 1,2-bis(2-aminophenoxy)ethane-N-N-N'$N^{\prime}$-tetraacetic acid (BAPTA) did not activate the motility of spermatozoa in medium 1 or the subsequent initiation of motility in medium 2 containing these agents. Similar results were obtained with gadolinium, which inhibits the stretchactivated channels (Yang and Sachs, 1989). Moreover, modifying the plasma membrane potential by incubating the spermatozoa with TPP (Gatti et al., 1990) did not trigger the motility or inhibit the sperm activation under conditions of low osmolality.

Incubation for 10 min in media lacking $\mathrm{Na}^{+}$or $\mathrm{K}^{+}$(i.e. glucose or choline chloride solutions with osmolalities of $390 \mathrm{mOsm} \mathrm{kg}^{-1}$ ) strongly decreases the percentage of motile spermatozoa when tested by transfer to a medium of low osmolality ( $170 \mathrm{mOsm} \mathrm{kg}^{-1}$ ) from $85 \%$ to $0-20 \%$ (Fig. 5 and Table 3). The same result was obtained using sodium isethionate. However, when such spermatozoa were transferred in distilled water (which has lower osmolality), the activation was triggered in $80-90 \%$ of the sperm population. This effect can be counteracted by an additional incubation for $10 \mathrm{~min}$ in glucose or choline chloride media supplemented with $100 \mathrm{mmol} \mathrm{l}^{-1} \mathrm{KCl}$ or NaCl: under these conditions $20-30 \%$ of spermatozoa were activated when tested in a medium with an osmolality of about $170 \mathrm{mOsm} \mathrm{kg}^{-1}$.

The effects of various agents that have been shown to have intracellular targets are shown (Table 4). Various concentrations of $\mathrm{NH}_{4} \mathrm{Cl}$ were used in an attempt to increase the intracellular pH (Gatti and Christen, 1985; Boitano and Omoto, 1991); similarly, lactate was added, as it has been shown to decrease the intracellular $\mathrm{pH}$ of bovine spermatozoa (Babcock et al., 1983): neither $\mathrm{NH}_{4} \mathrm{Cl}$ nor lactate trigger or affect carp spermatozoa motility. Two other compounds, $\mathrm{KHCO}_{3}$ and isobutyl methyl xanthine (IBMX) that raise the intracellular CAMP concentration by increasing the adenylate cyclase activity and inhibiting the phosphodiesterase, respectively (Schoff and First, 1995) had no effect on motility of carp spermatozoa.

However, DMSO (from I to $20 \% \mathrm{v} / \mathrm{v}$ ) triggered motility after incubation for 3-4 min in media with an osmolality of $400-3200 \mathrm{mOsm} \mathrm{kg}^{-1}$. In contrast, $0-1 \%$ DMSO did not trigger sperm motility under the same conditions. Motile spermatozoa in DMSO solutions swell and progressively showed a curling in the distal portion of the flagellum. The increase in volume of the motile spermatozoa remains the same $(200 \%)$ irrespective of the DMSO concentration in the range 1-20\% (Fig. 6).

\section{Discussion}

Intact carp spermatozoa are maintained immotile when the extracellular environment has an osmolality higher than 250$300 \mathrm{mOsm} \mathrm{kg}{ }^{-1}$ : this corresponds to solutions containing $0.15 \mathrm{~mol}$ salt $\mathrm{I}^{-1}$ or $0.25 \mathrm{~mol}$ glucose $\mathrm{l}^{-1}$ and to the osmolality of the seminal plasma $\left(286 \mathrm{mOsm} \mathrm{kg}^{-1}\right.$ : Plouidy and Billard, 1982; $300 \mathrm{mOsm} \mathrm{kg}^{-1}$ : Morisawa et al., 1983b). Whatever the external medium composition, motility is triggered in more than $95 \%$ of spermatozoa when the osmolality is less than $200 \mathrm{mOsm} \mathrm{kg}^{-1}$. We observed that the value of the sperm velocity is quite similar in all the solutions, irrespective of the presence of ions. These resuits contrast with a higher score of both motility and velocity of intact spermatozoa in a $\mathrm{KCl}$ medium reported by Morisawa et al. (1983b).

Carp spermatozoa can be demembranated by Triton X-100, which allows the axonemal machinery to come directly into contact with the external environment (Cosson and Gagnon, 1988). The highest percentage of motile spermatozoa and the highest velocity occurred when the reactivating solution contained 0.05 to $0.20 \mathrm{~mol} \mathrm{salt} \mathrm{l}^{-1}$ (140 to $400 \mathrm{mOsm} \mathrm{kg}{ }^{-1}$ ). With respect to these two parameters, the better reactivation is observed at $0.10 \mathrm{~mol} \mathrm{l}^{-1}$ (about $220 \mathrm{mOsm} \mathrm{kg}^{-1}$ ). Intact spermatozoa are optimally activated at osmolalities of 60 to $140 \mathrm{mOsm} \mathrm{kg}^{-1}$. The present results contrast with the recent 


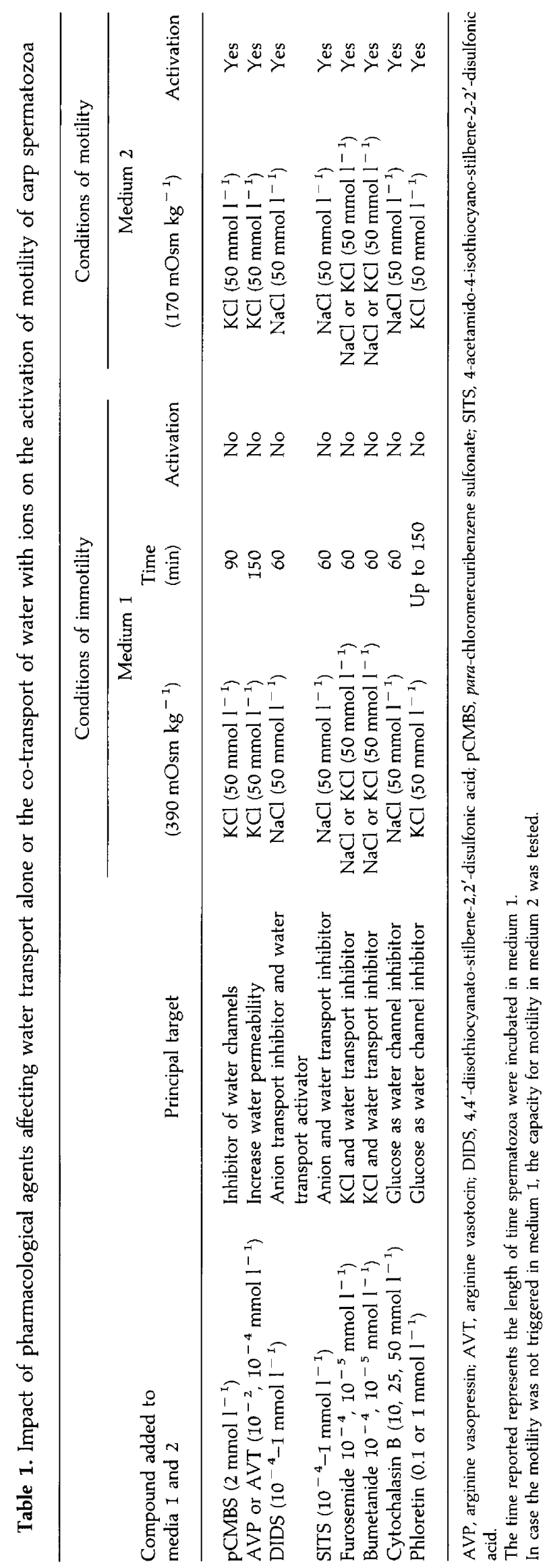




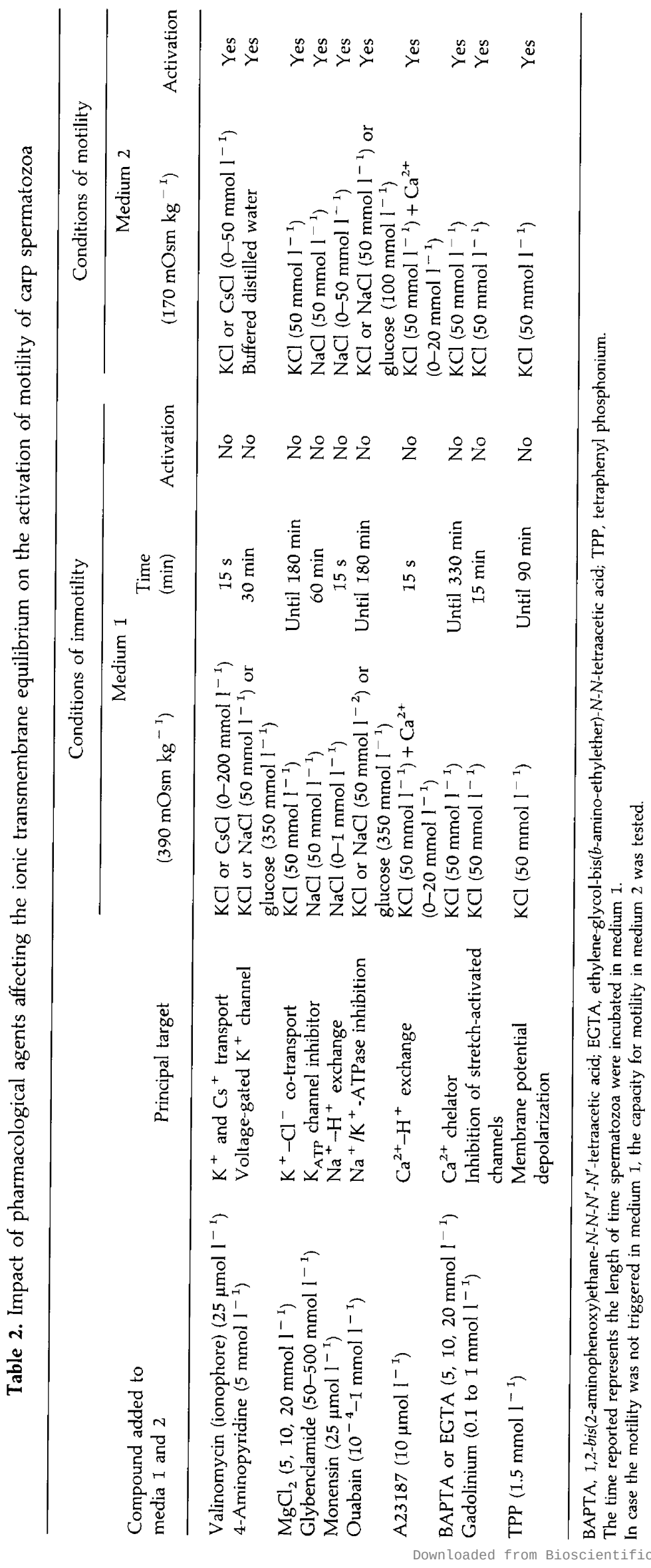




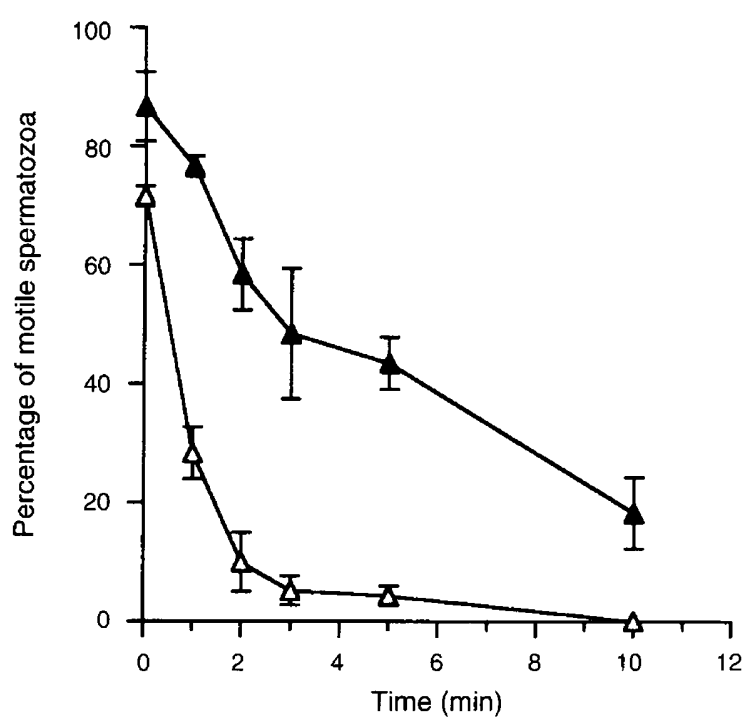

Fig. 5. Variation in the percentage of motile carp spermatozoa as a function of time after suspension in glucose $(\boldsymbol{\Delta})$ or choline chloride $(\triangle)$ medium with high osmolality $\left(390 \mathrm{mOsm} \mathrm{kg}^{-2}\right)$. Spermatozoa were activated in media containing the same compounds but with low osmolality ( $170 \mathrm{mOsm} \mathrm{kg}^{-1}$ ). Values are means \pm SEM; $n=3$ males).

observation of Morisawa (1994) that demembranated axonemes in the spermatozoa of the freshwater zebrafish are resistant to reactivation at low osmolality $\left(0.05 \mathrm{~mol} \mathrm{KCl}^{-1}\right)$ and are fully reactivated at high osmolality $\left(0.15 \mathrm{~mol} \mathrm{KCl} \mathrm{l}^{-1}\right)$; this tends to show that direct control of axonemal movement by osmolality is not a general rule among different fish species. These results on freshwater fish are slightly different from those reported for sea urchin spermatozoa (Gibbons and Gibbons, 1972), which are reactivated most readily in solutions containing 0.15 to $0.25 \mathrm{~mol}$ salt $1^{-1}$.

It appears that the ionic composition of the medium is more important for motility in reactivated than in intact spermatozoa. While intact spermatozoa showed similar motility whatever the ionic composition of the external medium of low osmolality, the velocity of demembranated spermatozoa depends on the type of cation included in the medium. At the axoneme, $\mathrm{K}^{+}$and $\mathrm{Na}^{+}$have a more crucial role than choline, perhaps due to their small size. Moreover, in contrast to intact spermatozoa, the very low ionic strength of a glucose medium maintains the immotility of demembranated spermatozoa. Ionic interactions are needed to maintain the cohesion between the axonemal compounds and the dynein ATPase responsible for the flagellar beating. These results confirm those already reported by Gibbons and Gibbons (1972) for sea urchin spermatozoa. On the other hand, increasing the salt concentration slightly increases the viscosity of the medium, which may in turn significantly decrease the velocity of reactivated spermatozoa. Moreover, a medium with a higher ionic strength decreases the frequency of axonemal movement due to a partial extraction of the outer dynein arm (Gibbons and Gibbons, 1973). The immotile axoneme in solutions of low or high ionic strength can be rendered motile by the addition or difution of ions, respectively (data not shown). These results suggest that variations in the extracellular osmolality is not directly detected by the axoneme because the plasma membrane acts as a barrier. However, the mechanisms by which the external osmotic signal is transduced into a biochemical intracellular signal that in turn activates the dynein ATPases remains to be elucidated.

In response to an external osmotic signal, carp spermatozoa change their internal volume (this also occurs in erythrocytes (Dickman and Golstein, 1990), yeast (Berner and Gervais, 1994) and mammalian spermatozoa (Crichton et al., 1994)). The final volume reached by carp spermatozoa depends on the extracellular osmolality and is independent of the major ion present in the surrounding solution. It appears that in carp, sperm swelling parallels the activation of motility: the threshold of osmolality between motility or swelling and the activation or inhibition of motility is $200-300 \mathrm{mOsm} \mathrm{kg}{ }^{-1}$ and probably reflects an equilibrium; it suggests that intracellular osmolality of carp spermatozoa is $200-300 \mathrm{mOsm} \mathrm{kg}^{-1}$. It is worth noting that this value does not inhibit the flagellar beating after demembranation, suggesting that the intracellular osmolality is higher than the extracellular osmolality.

The hypo-osmotic stress induces a gradient of concentration between the intracellular and extracellular medium and the sperm cell attempts to balance the osmolality on both sides of the plasma membrane by an influx of water. The subsequent increase in carp sperm volume (at about $60 \mathrm{~s}$ ) is slower than that measured for human spermatozoa which occurs after $30 \mathrm{~s}$ (Noiles et al., 1993), or of erythrocytes which occurs after 3-4 s; (Liu et al., 1995) in hypo-osmotic medium. A water channel protein (aquaporin) named CHIP28 has been isolated and characterized in erythrocyte membranes (reviewed by Agre $e$ al., 1993). This water channel does not seem to occur in carp spermatozoa because pCMBS, a specific inhibitor of CHIP28 (Lahajnar et al., 1995), did not interfere with their motility. Moreover, phloretin and cytochalasin B, two potent inhibitors of the glucose transporter (GLUT), which acts as a water channel in Xenopus oocytes (Fischbarg et al., 1990), and perhaps in mammalian spermatozoa (Curry et al., 1995), does not interfere with the activation process of carp spermatozoa. The use of arginine vasopressin (AVP) or arginine vasotocin (AVT), which increases the water permeability of inner medullary collecting ducts (Nielsen et al., 1993), does not trigger the activation of carp spermatozoa. However, the action of AVP or AVT needs a specific plasma membrane receptor, which may not occur in carp spermatozoa. Inhibition of water and ion co-transport in epithelium by furosemide or bumetanide (Zeuthen and Stein, 1994) has no effect on carp sperm motility. Similarly, the inhibition of co-transport of water and anions using DIDS (Tanimoto and Morisawa, 1988; Blank et al, 1994) or SITS (Korchak et al., 1980) does not trigger or inhibit the activation of motility of carp spermatozoa. Thus, the passive diffusion of water across the plasma membrane alone could explain the slow entrance of water, as is the case for human spermatozoa (Curry et al., 1995; Liu et al., 1995). Moreover, in contrast to erythrocytes (Lauf, 1982) or to bacteria (Csonka, 1989) both of which can readjust their internal volume by changing the intracellular electrolyte or non-electrolyte solute concentration, the swelling of carp spermatozoa is not regulated and sperm cells shrink only if the external osmolality increases. These results suggest that a water channel or water and ion co-transport do not have a major role in the activation process. Moreover, because the swelling of carp spermatozoa is 
Table 3. Media affecting the activation of motility of carp spermatozoa

\begin{tabular}{|c|c|c|c|c|c|c|}
\hline \multirow[b]{3}{*}{$\begin{array}{l}\text { Principal compound } \\
\text { of media } I\end{array}$} & \multirow[b]{3}{*}{$\begin{array}{c}\text { Principal } \\
\text { characteristic }\end{array}$} & \multicolumn{3}{|c|}{ Conditions of immotility } & \multicolumn{2}{|c|}{ Conditions of motility } \\
\hline & & \multicolumn{3}{|c|}{ Media I } & \multicolumn{2}{|l|}{ Media 2} \\
\hline & & $\left(390 \mathrm{mOsm} \mathrm{kg}^{-1}\right)$ & $\begin{array}{l}\text { Time } \\
(\mathrm{min})\end{array}$ & Activation & $\left(170 \mathrm{mOsm} \mathrm{kg}^{-1}\right)$ & Activation \\
\hline Glucose $\left(350 \mathrm{mmol} \mathrm{l}^{-1}\right)$ & Non-ionic medium & Tris- $\mathrm{HCl}\left(30 \mathrm{mmol} \mathrm{I}^{-1}\right)$ & 10 & No & $\mathrm{KCl}\left(50 \mathrm{mmol} \mathrm{l}^{-1}\right)$ & No \\
\hline & & & & & Tris- $\mathrm{HCl}\left(30 \mathrm{mmol} \mathrm{l}^{-1}\right)$ & Yes \\
\hline $\begin{array}{l}\text { Choline chloride } \\
\left(200 \mathrm{mmol} \mathrm{l}^{-1}\right)\end{array}$ & Medium without major & Tris- $\mathrm{HCl}\left(30 \mathrm{mmol} \mathrm{I}^{-\mathrm{I}}\right)$ & 10 & No & $\mathrm{KCl}\left(50 \mathrm{mmol} \mathrm{l}^{-1}\right)$ & No \\
\hline Sodium isethionate & $\begin{array}{l}\text { cation } \\
\text { Medium without chloride }\end{array}$ & Hepes (30 $\left.\mathrm{mmol} \mathrm{l}^{-1}\right)$ & 20 & No & $\begin{array}{l}\text { Tris- } \mathrm{HCl}\left(30 \mathrm{mmol} \mathrm{l^{-1 }}\right) \\
\text { Sodium isethionate } \\
\left(50 \mathrm{mmol} 1^{-1}\right)\end{array}$ & $\begin{array}{l}\text { Yes } \\
\text { No }\end{array}$ \\
\hline DMSO $1-20 \%$ & $\begin{array}{l}\text { Diluant/membrane } \\
\text { interaction/intracellular } \\
\text { water }\end{array}$ & $\mathrm{KCl}\left(50 \mathrm{mmol} \mathrm{l}^{-1}\right)$ & 3 & Yes & Hepes $\left(30 \mathrm{mmol} \mathrm{l}^{-1}\right)$ & Yes \\
\hline
\end{tabular}

DMSO, dimethylsulfoxide.

The time reported represents the length of time spermatozoa were incubated in medium I.

In case the motility was not triggered in medium 1, the capacity for motility in medium 2 was tested.

Table 4. Effect of pharmacological agents, which are known to have intracellular targets, on the motility of carp spermatozoa

\begin{tabular}{|c|c|c|c|c|c|c|}
\hline \multirow{3}{*}{$\begin{array}{l}\text { Compound added to } \\
\text { media } 1 \text { and } 2\end{array}$} & \multirow[b]{3}{*}{ Principal target } & \multicolumn{3}{|c|}{ Conditions of immotility } & \multicolumn{2}{|c|}{ Conditions of motility } \\
\hline & & \multicolumn{3}{|c|}{ Medium I } & \multicolumn{2}{|c|}{ Medium 2} \\
\hline & & $\left(390 \mathrm{mOsm} \mathrm{kg}^{-1}\right)$ & $\begin{array}{l}\text { Time } \\
\text { (min) }\end{array}$ & Activation & $\left(170 \mathrm{mOsm} \mathrm{kg}^{-1}\right)$ & Activation \\
\hline $\mathrm{NH}_{4} \mathrm{Cl}\left(5,10,20 \mathrm{mmol} \mathrm{l}^{-1}\right)$ & Increase $\mathrm{pH}_{\mathrm{i}}$ & $\mathrm{KCl}\left(50 \mathrm{mmol} \mathrm{I}^{-1}\right)$ & Until 180 & No & $\mathrm{KCl}\left(50 \mathrm{mmol} !^{-1}\right)$ & Yes \\
\hline Lactate $\left(0.06-0.6 \mathrm{mmol} \mathrm{l}^{-1}\right)$ & Decrease $\mathrm{pH}_{\mathrm{i}}$ & $\mathrm{KCl}\left(50 \mathrm{mmol} \mathrm{I}^{-1}\right)$ & 60 & No & $\mathrm{KCl}\left(50 \mathrm{mmol} \mathrm{i}^{-1}\right)$ & Yes \\
\hline $\operatorname{IBMX}\left(1,2 \mathrm{mmol} \mathrm{l}^{-1}\right)$ & Phosphodiesterase inhibitor & $\mathrm{KCl}\left(50 \mathrm{mmol} \mathrm{l}^{-1}\right)$ & 90 & No & $\mathrm{KCl}\left(50 \mathrm{mmol} \mathrm{l}^{-1}\right)$ & Yes \\
\hline $\mathrm{KHCO}_{3}\left(5,10,20 \mathrm{mmol} \mathrm{l}^{-\mathrm{I}}\right)$ & Adenylate cyclase activation & $\mathrm{KCl}\left(50 \mathrm{mmol} \mathrm{l}^{-1}\right)$ & Until 180 & No & $\mathrm{KCl}\left(50 \mathrm{mmol} \mathrm{l}^{-1}\right)$ & Yes \\
\hline
\end{tabular}

IBMX, isobuthyl methyl xanthine, $\mathrm{pH}_{\mathrm{i}}$, intracellular $\mathrm{pH}$.

The time reported represents the length of time spermatozoa were incubated in medium 1 .

In case the motility was not triggered in medium 1 , the capacity for motility in medium 2 was tested.

a progressive phenomenon that occurs much later than initiation of movement, the entrance of water is neither the first nor the major event triggering motility.

The time taken for spermatozoa to shrink in a medium of high osmolality is rapid (3-4s) compared with the time required for the swelling in distilled water: this suggests a difference in membrane permeability on both sides of the membrane. The change in size of the flagellum and midpiece in media of various osmolality could not be measured but it is assumed that it undergoes the same decrease or increase as the size of the head. A decrease in the sperm volume probably limits the intracellular space located between the axonemal machinery and the plasma membrane. This change could be involved in the inactivation process by inducing some mechanical constraints and/or by limiting the exchange between shuttle molecules (like phosphocreatine in trout spermatozoa; Robitaille et al., 1987) and local energy.

When the ionic permeability was modified using ionophores or when the ionic environment of the plasma membrane was modified, no marked effect on carp sperm motility was observed. Among the ionophores previously shown to affect the initiation of motility in sea urchin spermatozoa through the $\mathrm{Na}^{+}-\mathrm{H}^{+}$exchange (monensin; Shackmann and Chock, 1986) or that of trout spermatozoa through $\mathrm{K}^{+}$transport (valinomycin; Boitano and Omoto, 1991), neither have any impact on carp sperm motility. It is worth noting that sea urchin and trout spermatozoa are both activated through an ionic exchange across the plasma membrane (for review, see Gatti and Dacheux, 1995). By manipulating the intracellular $\mathrm{Ca}^{2+}$ concentration with the ionophore A23187, spermatozoa of the marine puffer fish can be activated (Oda and Morisawa, 1993). Similar treatment does not activate carp sperm motility when the extracellular concentration is decreased by the addition of the calcium chelator BAPTA or EGTA. Manipulating the transport of $\mathrm{K}^{+}$through channels with glybenclamide (Wangemann et al., 1992; Han et al., 1993) or 4-aminopyridine (Krasznai et al., 1995) does not trigger the motility of carp spermatozoa in media of high osmolality. However, as 4-aminopyridine decreases the intracellular ATP content (data not shown), it decreases the duration of motility which suggests a direct Downloaded from Bioscientifica.com at 04/26/2023 10:12:18AM 


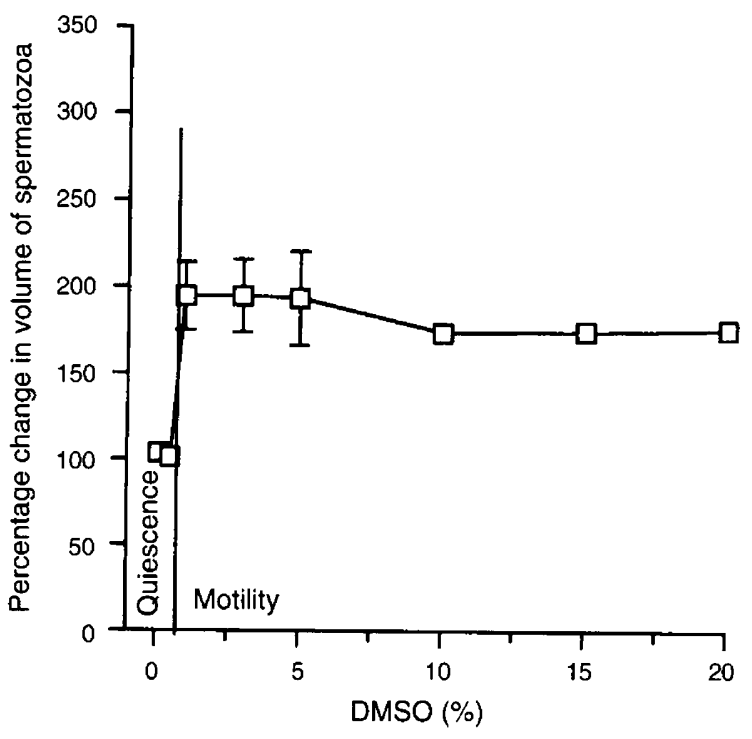

Fig. 6. Percentage change in the volume of carp spermatozoa determined by a spermatocrit method. Spermatozoa were suspended in media containing various concentrations of dimethylsulfoxide (DMSO). The medium containing a very low percentage of DMSO contained glucose to adjust the osmolality to $400 \mathrm{mOsm} \mathrm{kg}^{-1}$. The straight line represents the barrier between activation of motility or quiescence. Each datum point represents the average of two samples, each of which was obtained by pooling two different milt. At least two measurements were made per sample. Values are means $\pm \mathrm{SD}$.

action at the mitochondria. Inhibition of the co-transport of $\mathrm{Na}^{+}$interferes with carp sperm motility as is the case for sea urchin spermatozoa (Nelson, 1982; Gatti and Christen, 1985). Manipulating the membrane potential with TPP has no effect on carp sperm motility. However, ions are necessary for the signal transduction since a prolonged exposure to a medium devoid of major ions (i.e. glucose, choline chloride or sodium isethionate) decreases the osmotic threshold of activation: after such treatment spermatozoa became motile only in buffered distilled water. Nevertheless, the addition of $\mathrm{NaCl}$ or $\mathrm{KCl}$ $\left(100 \mathrm{mmol} \mathrm{I}^{-1}\right)$ for an additional period of $10 \mathrm{~min}$ restores the motility in media 2 for $20-30 \%$ of spermatozoa, suggesting that these ions are involved in the transduction of the osmotic signal. Moreover, incubation of carp spermatozoa with a buffered medium containing $200 \mathrm{mmol} \mathrm{KCl}{ }^{-1}$ (osmolality: $390 \mathrm{mOsm} \mathrm{kg}{ }^{-1}$ ) for a few hours progressively leads to the activation of spermatozoa in medium with increasing osmolality (up to $250 \mathrm{mOsm} \mathrm{kg}{ }^{-1}$ ) by modulating the threshold of perception of the osmotic signal (Redondo-Müller, 1990; G. Perchec Poupard, personal observations). A simple $\mathrm{K}^{+}$transport across the plasma membrane is not the factor responsible for the activation process as shown by the results obtained with valinomycin; however, $\mathrm{K}^{+}$and $\mathrm{Cl}^{-}$(see results with sodium isethionate) seem to be involved in the perception of the osmotic signal by the membrane.

Although altering the cellular second messengers (via $\mathrm{pH}$ or (AMP) in sea urchin, trout, puffer fish and mammalian spermatozoa interferes with motility, it has no impact on carp sperm motility. Activation of carp spermatozoa appears to be independent of the intracellular $\mathrm{pH}$ since the addition of $\mathrm{NH}_{4} \mathrm{Cl}$ does not trigger sperm motility as occurs in sea urchin spermatozoa (Christen et al., 1982). Moreover, carp sperrn motility can be initiated in a similar way in media of pH 6.0-9.0 (Redondo-Müller et al., 1991). Similarly, it has been shown that changing the external $\mathrm{pH}$ value induces a change in the intracellular $\mathrm{pH}$ of boar, ram and trout spermatozoa (Gatti et al., 1990, 1993). The results reported here are in agreement with those of Krasznai et al. (1995), who observed that the intracellular alkalinization (by $0.15 \mathrm{pH}$ units) that accompanied the initiation of motility of carp spermatozoa does not play a regulatory role in triggering axonemal movement. Similar results have been shown for the regulation of motility of trout spermatozoa (Gatti et al., 1990; Boitano and Omoto, 1991). The addition of IBMX, a phosphodiesterase inhibitor, does not stimulate carp sperm motility, in contrast to its effect on bovine spermatozoa (Schoff and First, 1995). As for intracellular pH, cAMP does not seem to be a second messenger able to trigger carp sperm motility, in contrast to its role in trout spermatozoa (Morisawa and Okuno, 1982). Other experiments support this finding since the reactivation of demembranated carp spermatozoa using $\mathrm{Mg}-\mathrm{ATP}$ does not require the addition of cAMP (Cosson and Gagnon, 1988). Moreover, it has been shown that intracellular concentrations of cAMP and $\mathrm{Ca}^{2+}$ increase in intact trout spermatozoa after activation; both compounds are necessary in the demembranation-reactivation experiment with trout spermatozoa which is not the case for carp spermatozoa (Morisawa and Ishida, 1987; Cosson et al., 1989; Boitano and Omoto, 1991).

Surprisingly, DMSO can trigger carp sperm motility in some conditions that are not permissive for motility in its absence. Nevertheless, it has previously been used extensively as a cryopreservative: the use of DMSO to cryopreserve carp spermatozoa could explain why they have a poor capacity for motility initiation after such treatment (Cognie et al., 1989). DMSO relieves the inhibition of movement due to the high osmolality (300-400 mOsm kg ${ }^{-1}$ ) of medium 1 . In the same way, DMSO has been shown to enhance the motility of sea urchin spermatozoa (Steinbach, 1966). Because carp spermatozoa swell following the addition of DMSO, it has been suggested that an influx of water occurs. However, the extent of this swelling is limited and a threshold is reached and sustained over a large range of concentration of DMSO. In contrast to the results presented here, DMSO induces a reduction of the intracellular water content of fowl spermatozoa, and a cell shrinking is observed using the same range of concentration as that used in the present study (Terada et al., 1988). However, the mechanism by which DMSO triggers carp sperm motility is quite difficult to explain because the impact of DMSO on a cell is not fully understood. DMSO has a high membrane permeability and it is generally accepted that its entry into the cell is fast. The delayed response observed in this study for the activation of motility by DMSO (3-4 min after mixing) suggests that changes other than the influx of DMSO into spermatozoa are involved. Various effects of DMSO have been reported. In cells in general, this cryoprotectant has water-binding properties and prevents ice crystal formation. DMSO also acts on mitogenic signal transduction during the early developmental stages of mouse embryos (Ganapathy and Shanmugam, 1995). Moreover, DMSO can interact with phospholipid membranes as well as with isolated proteins (Anchordoguy et al., 1991). It is possible that DMSO alters the 
lipid bilayer structure of the sperm membrane; in this respect Marian et al. (1993) propose that a reorganization of the lipid bilayer structure of the plasma membrane of the carp spermatozoa is essential in transmembrane signalling.

In conclusion, our experiments show that the osmotic signal transduction that activates carp spermatozoa is totally different from the mechanisms previously described for the spermatozoa of other species such as sea urchin or trout. The extracellular osmotic signal could act through a change in intracellular osmolality as the factor triggering motility. Nevertheless, the implication of an intracellular effector(s) dilution seems to be ruled out since the entrance of water is a progressive phenomenon that occurs some time after motility is triggered. For the same reason, the influx of water alone does not trigger motility but probably follows a previous ionic transport across the plasma membrane. All the ions were studied in turn; a co-transport or a coupling between different ions has not been excluded. The measurement of the ionic flux should give more information. As carp spermatozoa are sensitive to variation in osmotic pressure, stretch-activated (Sachs and Sokabe, 1990) or mechanically activated channels (Opsahl and Webb, 1994), which are highly sensitive to membrane tension or pressure and which modify the activity of certain membrane proteins (Vandorpe et al., 1994), could be involved in the activation. Gadolinium, which has no effect on motility and which inhibits stretch-activated channels, is not totally specific for these channels (Sachs and Sokabe, 1990), and the use of patch clamps on carp spermatozoa, as described for sea urchin spermatozoa (Darzon et al., 1987) should give more information. Finally, studies on the way in which DMSO can bypass the extraceliular osmotic barrier and trigger the motility of carp spermatozoa will give more insight into this mechanism.

\section{References}

Agre P, Preston GM, Smith BL, Jung JS, Raina S, Moon C, Guggino WB and Nielsen S (1993) Aquaporin CHIP: the archetypal molecular water channel American Journal of Physiology 265 F463-476

Anchordoguy TJ, Cecchini CA, Crowe JH and Crowe LM (1991) Insights into the cryoprotective mechanism of dimethyl sulfoxide for phospholipid bilayers Cryobiology 28 467-473

Babcock DF, Rufo GA and Lardy HA (1983) Potassium-dependent increases in cytosolic $\mathrm{pH}$ stimulate metabolism and motility of mammalian sperm Proceedings of the National Academy of Sciences USA 80 1327-1331

Berner JL and Gervais P (1994) Yeast cells submitted to osmotic shifts Biotechnology and Bioengineering 43 165-170

Billard R (1978) Changes in structure and fertilizing ability of marine and freshwater fish spermatozoa diluted in media of various salinities Aquaculture 14 187-198

Blank ME, Hoefner DM and Diedrich DF (1994) Morphology and volume alterations of human erythrocytes caused by the anion transporter inhibitors, DIDS and p-azidobenzylphlorizin Biochimica et Biophysica Acta 1192 223233

Boitano S and Omoto CK (1991) Membrane hyperpolarization activates trout sperm without an increase in intracellular $\mathrm{pH}$ Journal of Cell Science $\mathbf{9 8}$ 343-349

Boitano S and Omoto CK (1992) Trout sperm swimming patterns and role of intracellular $\mathrm{Ca}^{++}$Cell Motility and the Cytoskeleton 21 74-82

Chrichton EG, Hinton BT, Pallone TL and Hammerstedt RH (1994) Hyperosmolality and sperm storage in hibernating bats: prolongation of sperm life by dehydration American Journal of Physiology 267 R1363-1370

Christen R, Schackmann RW and Shapiro BM (1982) Elevation of the intracellular $\mathrm{pH}$ activates respiration and motility of sperm of the sea urchin, Strongylocentrotus purpuratus. Journal of Biological Chemistry $25714881-$ 14890
Christen R, Schackmann RW and Shapiro BM (1986) lonic regulation of sea urchin sperm motility, metabolism and fertilizing capacity Journal of Physiology 379 347-365

Cognie F, Billard R and Chao NH (1989) La cryoconservation de la laitance de la carpe, Cyprinus carpio. Journal of Applied Ichthyology 5 165-176

Cosson MP and Gagnon C (1988) Protease inhibitor and substrates block motility and microtubule sliding of sea urchin and carp spermatozoa Cell Motility and the Cytoskeleton 10 518-527

Cosson MP, Billard R and Letellier L (1989) Rise of internal $\mathrm{Ca}^{2+}$ accompanies the initiation of trout sperm motility Cell Motility and the Cytoskeleton 14 $424-4.34$

Csonka LN (1989) Physiological and genetic responses of bacteria to osmotic stress Microbiological Review 53 121-147

Curry MR, Millar JD and Watson PF (1995) The presence of water channel proteins in ram and human sperm membranes Journal of Reproduction and Fertility 104 297-303

Darszon A, Garcia-soto J, Gonzalez M, Guerrero A, Sanchez JA and Lievano A (1987) Ion transport mechanism in sea urchin sperm. In New Horizons in Sperm Cell Research pp 169-183 Ed. H Mohri. Tokyo/Gordon and Breach Science Publisher, New York

Dickman KG and Goldstein L (1990) Cell volume regulation by skate erythrocytes: role of potassium American Journal of Physiology 258 R1217-1223

Fischbarg J, Kuang K, Vera JC, Arant S, Silverstein SC, Loike J and Rosen OM (1990) Glucose transporters serve as water channels Proceedings of the National Academy of Sciences USA 87 3244-3247

Ganapathy P and Shanmugam G (1995) Dimethyl sulfoxide alters mitogen induced production of diacylglycerol and GTP-binding to plasma membranes in mouse embryo fibroblasts Biochemical Molecular Biology International 35 739-748

Gatti JL and Christen R (1985) Regulation of internal pH of sea urchin sperm journal of Biological Chemistry $2607599-7602$

Gatti JL and Dacheux JL (1995) Mécanismes membranaires du contrôle de la mobilité des spermatozoïdes. Rôle du plasma séminal et de l'environnement ionique Comptes rendus de l'Académie d'agriculture de France 5 167-176

Gatti JL, Billard R and Christen R (1990) lonic regulation of the plasma membrane potential of rainbow trout (Salmo gairdneri) spermatozoa: role in the initiation of sperm motility Journal of Cell Physiology 143 546-554

Gatti JL, Chevrier C, Paquignon M and Dacheux JL (1993) External ionic conditions, internal pH and motility of ram and boar spermatozoa Journal of Reproduction and Fertility 98 439-449

Gibbons BH and Gibbons IR (1972) Flagellar movement and adenosine triphosphate activity in sea urchin sperm extracted with Triton X-100 Journal of Cell Biology 54 75-97

Gibbons BH and Gibbons IR (1973) The effects of partial extraction of dynein arms on the movement of reactivated sea-urchin sperm Journal of Cell Science $13337-357$

Han J, So I, Kim EY and Earm YE (1993) ATP-sensitive potassium channels are modulated by intracellular lactate in rabbit ventricular myocytes Pflügers Archives 425 546-548

Hansbrough JR and Garbers DL (1981) Sodium-dependent activation of sea urchin spermatozoa by speract and monensin Journal of Biological Chemistry $2562235-2241$

Hosono K (1992) Effect of salt stress on lipid composition and membrane fluidity of the salt-tolerant yeast Zygosaccharomyces rouxii. Joumal of General Microbiology 8 91-96

Korchak HM, Eisenstat BA, Hoffstein ST, Dunham PB and Weissmann G (1980) Anion channel blockers inhibit lysosomal enzyme secretion from human neutrophils without affecting generation of superoxide anion Proceedings of the National Academy of Sciences USA $772721-2725$

Krasznai Z, Marian T, Balkay L, Gaspar R and Tron L (1995) Potassium channels regulate hypo-osmotic shock-induced motility of common carp (Cyprinus carpio) sperm Aquaculture 129 123-128

Lahajnar G, Macek P, Smid P and Zupancic I (1995) Ethanol- and acetonitrileinduced inhibition of water diffusional permeability across bovine red blood cell membrane Biochimica et Biophysica Acta 1235 437-442

Lauf $P$ (1982) Evidence for chloride dependent potassium and water transport induced by hyposmotic stress in erythrocytes of the marine teleost, Opsanus tau. Journal of Comparative Physiology 146 9-16

Lauf PK, Bauer J, Adragna NC, Fujise H, Zade-oppen AMM, Ryu KH and Delpire E (1992) Erythrocyte $\mathrm{K}-\mathrm{Cl}$ cotransport: properties and regulation American Journal of Physiology 263 C917-932 
Liu C, Gao D, Preston GM, McGann L, Benson CT, Critser ES and Critser JK (1995) High water permeability of human spermatozoa is mercury-resistant and not mediated by CHIP28 Biology of Reproduction 52 913-919

Marian T, Krasznai Z, Balkay L, Balazs M, Emri M, Bene L and Tron L (1993) Hypo-osmotic shock induces an osmolality-dependent permeabilization and structural changes in the membrane of carp sperm Journal of Histochinny and Cytochimy 41 291-297

Morisawa M (1994) Cell signaling mechanisms for sperm motility Zoological Science 11 647-662

Morisawa M and Ishida K (1987) Short-term changes in the levels of cyclic AMP, adenylate cyclase, and phosphodiesterase during the initiation of sperm motility in rainbow trout Journal of Experimental Zoology 242 199-204

Morisawa M and Okuno M (1982) Cyclic AMP induces maturation of trout sperm axoneme to initiate motility Nature 295 703-704

Morisawa M, Susuki K and Morisawa S (1983a) Effects of potassium and osmolality on spermatozoan motility of salmonid fishes Journal of Experimental Biology 107 105-113

Morisawa M, Susuki K, Shimizu H, Morisawa S and Yasuda K (1983b) Effects of osmolality and potassium on motility of spermatozoa from freshwater cyprinid fishes Journal of Experimental Biology 107 95-103

Nelson L (1982) Membrane-stabilizing and calcium-blocking agents affect Arbacia sperm motility Biological Bulletin 163 492-503

Nielsen S, Muller J and Knepper MA (1993) Vassopressin- and cAMP-induced changes in ultrastructure of isolated perfused inner medullary collecting ducts American Journal of Physiology 265 F225-238

Noiles EE, Mazur P, Watson PF, Kleinhans FW and Critser JK (1993) Determination of water permeability coefficient for human spermatozoa and its activation energy Biology of Reproduction 48 99-109

Oda S and Morisawa M (1993) Rises of intracellular $\mathrm{Ca}^{2+}$ and $\mathrm{pH}$ mediate the initiation of sperm motility by hyperosmolality in marine teleosts Cell Motility and the Cytoskeleton 25 171-178

OpsahI LR and Webb WW (1994) Transduction of membrane tension by the ion channel alamethicin Biophysical Journal 66 71-74

Perchec G, Chauvaud L, Suquet M, Cosson J, André F and Billard R (1993) Evolution des caractéristiques du mouvement et de la teneur en ATP au cours de la période de mobilité de spermatozodes de carpe et de turbot, poissons téléostéens Comptes rendus de l'Académie d'agriculture de France 6 $117-126$

Perchec G, Jeulin C, Cosson J, André F and Billard R (1995) Relationship between sperm ATP content and motility of carp spermatozoa Journal of Cell Science $108747-753$

Perchec G, Cosson MP, Cosson J, Jeulin C and Billard R (1996) The morphological and kinetic changes of carp (Cyprinus carpio) spermatozoa after initiation of motility in distilled water Cell Motility and the Cytoskeleton 35 113-120

Plouidy MG and Billard R (1982) The chemical composition and the companion fluids of the gametes in the common carp (Cyprinus carpio). In Reproductive Physiology of Fish p. 134 Eds H Goos and C Richter. Pudoc, Wageningen
Redondo-Müller C (1990) Biologia del esperma de la carpa comun, Cyprinus carpio L, y del Siluro Europeo, Silurus Glanis L. Thèse de doctorat, Université de Zaragose (Espagne)

Redondo-Müller C, Cosson MP, Cosson J and Billard R (1991) In vitro maturation of the potential for movement of carp spermatozoa Molecular Reproduction and Development 29 259-270

Robitaille PM, Mumford KG and Brown G (1987) ${ }^{31} \mathrm{P}$ nuclear magnetic resonance study of trout spermatozoa at rest, after motility, and during short-term storage Biochemistry and Cell Biology 65 474-485

Sachs F and Sokabe M (1990) Stretch-activated ion channels and membrane mechanics Neuroscience Research 12 S1-S4

Shackmann RW and Chock PB (1986) Alteration of intracellular $\left[\mathrm{Ca}^{+2}\right]$ in sea urchin sperm by the egg peptide speract Journal of Biological Chemistry 261 8719-8728

Schoff PK and First NL (1995) Manipulation of bovine sperm metabolism and motility using anoxia and phosphodiesterase inhibitors Cell Motility and the Cytoskeleton 31 140-146

Steinbach HB (1966) The effects of glycerol and other organic solutes on the motility and respiration of some invertebrate spermatozoa Biological Bulletin 131 166-171

Stoss J (1983) Fish gamete preservation and spermatozoan physiology. In Fish Physiology IX pp 305-350 Eds WS Hoar, D Randall and EM Donaldson. Academic Press, New York/London

Takai $\mathrm{H}$ and Morisawa $\mathrm{M}$ (1995) Change in intracellular $\mathrm{K}^{+}$concentration caused by external osmolality change regulates sperm motility of marine and freshwater teleosts Journal of Cell Science 108 1175-1181

Tanimoto S and Morisawa M (1988) Roles of potassium and calcium channels in the initiation of sperm motility in rainbow trout Development Growth and Differentiation 30 117-124

Tanimoto S, Kudo Y, Nakazawa T and Morisawa M (1994) Implication that potassium flux and increase in intracellular calcium are necessary for the initiation of sperm motility in salmonid fishes Molecular Reproduction and Development 39 409-414

Terada T, Hashimoto H, Maeda T, Watanabe M and Tsutsumi Y (1988) Influence of cryoprotectant concentration on cell volume and motility of frozenthawed fowl spermatozoa Japonese Poultry Science 25 268-277

Vandorpe DH, Small DL, Dabrowski AR and Morris CE (1994) FMRamide and membrane stretch as activators of the Aplysia S-channel Biophysical Journal $6646-58$

Wangemann P, Shiga N, Welch C and Marcus DC (1992) Evidence for the involvement of a $\mathrm{K}^{+}$channel in isosmotic cell shrinking in vestibular dark cells American Journal of Physiology 263 C616-622

Yang XC and Sachs F (1989) Block of stretch-activated ion channels in Xenopus oocytes by gadolinium and calcium ions Science 243 1068-1071

Zeuthen T and Stein WD (1994) Cotransport of salt and water in membrane proteins: membrane proteins as osmotic engines Journal of Membrane Biology 137 179-195 